\title{
Research on the Current Eigenfrequencies for Motor with Bearing Fault and Mixed Eccentricity
}

\author{
J.H. Ma, C.D. Qiu, G.Z. Cheng, Z.Y. Xue \\ Marine Engineering College \\ Dalian Maritime University \\ Dalian, China
}

\begin{abstract}
The current feature for motor carried with natural mixed eccentricity and bearing fault is merely focused even though it is very important for motor online diagnosis. Considering both of the air-gap length change and torque vibration caused by bearing fault, the stator current expression were deduced for mixed eccentric motor. The new current characteristic frequencies for motor with bearing fault and mixed eccentricity were obtained. Finally, a series of simulation studies were conducted, the results show that the new eigenfrequencies are real and useful for online diagnosis of those motor in service.
\end{abstract}

Keywords-motor; eccentricity; bearing; fault

\section{INTRODUCTION}

Induction motor bearing faults can make the air-gap length change and cause torque vibration. Both the air-gap length change and torque vibration lead to the modulation to MMF(Magnetomotive Force), the work [1-2] analyze the characteristic frequency $\left(\left|f_{s} \pm k f_{c}\right|\right)$ related to the bearing fault in stator current spectrum; while the eccentric for motor is studied by analyzing the magnetic field in work [3-4], the eccentric characteristic frequency $\left(\left|f_{s} \pm k f_{r}\right|\right)$ can be found in stator current spectrum as well. However, the related studies on bearing fault are based on the ideal motor, namely, regardless of eccentric. It is well known that motor eccentric is inevitable because of the manufacturing and installation process. Hence, the current characteristic frequency of mixed eccentric motor with bearing fault is worth to be researched, and is helpful for online diagnosis of motor bearing fault.

\section{MOTOR ECCENTRICITY}

Eccentricity is caused by motor manufacturing and installation process and it is inevitable. Rotor eccentricity in induction motors takes two forms, namely, static eccentric (the rotor is displaced from the stator bore centre but is still turning upon its own axis) and dynamic eccentric (the rotor is still turning upon the stator bore centre but not on its own centre). According to the work [5], the air-gap length for the motor with mixed eccentricity can be expressed as follows

$$
g(\theta, t)=g_{0}\left[1-\delta_{s} \cos \theta-\delta_{d} \cos \left(\omega_{r} t-\theta\right)\right]
$$

Where $g_{0}$ is the motor designed air-gap length, $\delta_{s}$ is static eccentric degree, $\delta_{d}$ is dynamic eccentric degree, $\theta$ is the angle in stator frame, $\omega_{r}$ is the rotor angular.

It is clearly show that the air-gap length for motor with mixed eccentric has a relationship with the time and the rotor angular. The air-gap length change can cause the MMF change and the change of MMF will be analyzed later.

\section{CURRENT CHARACTERISTIC FREQUENCY FOR ECCENTRIC MOTOR}

The analysis below would be start with air-gap length change and torque vibration caused by bearing fault respectively.

\section{A. Air-Gap Length Change}

1) Outer raceway fault for mixed eccentric motor

When the motor with mixed eccentric has an outer raceway bearing fault, the air-gap length can be expressed as follows

$$
g_{o}(\theta, t)=g_{0}\left[1-\delta_{s} \cos \theta-\delta_{d} \cos \left(\omega_{r} t-\theta\right)\right]\left[1-e \cos \theta \sum_{k=-\infty}^{+\infty} \delta\left(t-\frac{k}{f_{o}}\right)\right](2)
$$

Where $e$ is eccentric degree caused by bearing fault, $\delta(t$ $k / f_{o}$ ) is Dirac function and $f_{o}$ is the characteristic frequency for an outer raceway fault.

For Dirac function, Fourier series method is used

$$
\sum_{k=-\infty}^{k=+\infty} \delta\left(t-\frac{k}{f_{o}}\right)=c_{0}+2 \sum_{k=1}^{+\infty} c_{k} \cos \left(2 \pi k f_{o} t\right)
$$

Where the Fourier series coefficients $c_{k}=f_{o} \forall k$.

Because the air-gap permeance $\Lambda$ is proportional to the inverse of the air-gap length, so the air-gap length can be defined as follows

$$
\Lambda(\theta, t)=\frac{\mu_{0}}{g_{0}\left[1-\delta_{s} \cos \theta-\delta_{d} \cos \left(\omega_{r} t-\theta\right)\right]\left[1-e \cos \theta \sum_{k=-\infty}^{+\infty} \delta\left(t-\frac{k}{f_{o}}\right)\right]}
$$

Where $\mu_{0}$ is the permeability of vacuum.

The formula $1 /(1-x)=1+x+x 2+\ldots \ldots, \quad(|x|<1)$ is used to simplify the equation (4)

$$
\begin{aligned}
\Lambda(\theta, t) & =\frac{\mu_{0}}{g_{0}}\left[1+\delta_{s} \cos \theta+\delta_{d} \cos \left(\omega_{r} t-\theta\right)\right. \\
& +e c_{0} \cos \theta-\delta_{s} e c_{0} \cos ^{2} \theta-e c_{0} \delta_{d} \cos \theta \cos \left(\omega_{r} t-\theta\right) \\
& +e \sum_{k=1}^{+\infty} c_{k} \cos \left(k \omega_{c} t-\theta\right)-e \delta_{s} \cos \theta \sum_{k=1}^{+\infty} c_{k} \cos \left(k \omega_{c} t-\theta\right) \\
& -e \delta_{d} \cos \left(\omega_{r} t-\theta\right) \sum_{k=1}^{+\infty} c_{k} \cos \left(k \omega_{c} t-\theta\right)+e \sum_{k=1}^{+\infty} c_{k} \cos \left(k \omega_{c}+\theta\right) \\
& \left.-e \delta_{s} \cos \theta \sum_{k=1}^{+\infty} c_{k} \cos \left(k \omega_{c}+\theta\right)-e \delta_{d} \cos \left(\omega_{r} t-\theta\right) \sum_{k=1}^{+\infty} c_{k} \cos \left(k \omega_{c}+\theta\right)\right]
\end{aligned}
$$


Only the fundamental MMF is taken into consideration and $\mathrm{MMF}$ is as follows

$$
F=F \cos \left(\omega_{s} t-p \theta+\varphi\right)
$$

Where $\mathrm{F}$ is the amplitude of fundamental MMF, $\omega_{\mathrm{s}}$ is power supply frequency and $\varphi$ is modulation angle.

The magnetic flux density can be obtained

$$
B(\theta, t)=F \Lambda(\theta, t)=F \Lambda_{0} \cos \left[\left(\omega_{s} \pm m \omega_{r} \pm n \omega_{c}\right) t \pm k \theta \pm \varphi\right]
$$

Where $\mathrm{m}=0,1 ; \mathrm{k}=0,1,2,3 \ldots \ldots ; \mathrm{n}=\mathrm{p}, \mathrm{p} \pm 1, \mathrm{p} \pm 2$.

Then according to the voltage equations of induction motor, the outer raceway fault characteristic frequency expression is shown below

$$
f_{\text {of }}=\left|f_{s} \pm m f_{r} \pm n f_{c}\right|
$$

Where $\mathrm{m}=0,1 ; \mathrm{k}=0,1,2,3 \ldots \ldots ; \mathrm{n}=\mathrm{p}, \mathrm{p} \pm 1, \mathrm{p} \pm 2$.

2) Inner raceway fault for mixed eccentric motor

When the motor with mixed eccentric has an inner raceway bearing fault, the air-gap length can be expressed as follows

$$
g_{i}(\theta, t)=g_{0}\left[1-\delta_{s} \cos \theta-\delta_{d} \cos \left(\omega_{r} t-\theta\right)\right]\left[1-e \cos \left(\omega_{r} t+\theta\right) \sum_{k=-\infty}^{+\infty} \delta\left(t-\frac{k}{f_{i}}\right)\right](9)
$$

Where $f_{i}$ is the characteristic frequency for an inner raceway fault.

The magnetic flux density can be obtained using method mentioned above

$B(\theta, t)=F \Lambda(\theta, t)=F \Lambda_{0} \cos \left[\left(\omega_{s} \pm m \omega_{r} \pm n \omega_{c}\right) t \pm k \theta+\varphi\right](10)$

Where $\mathrm{m}=0,1 ; \mathrm{k}=0,1,2,3 \ldots \ldots ; \mathrm{n}=\mathrm{p}, \mathrm{p} \pm 1, \mathrm{p} \pm 2$.

According to the voltage equations of induction motor, the inner raceway fault characteristic frequency expression is shown below

$$
f_{i f}=\left|f_{s} \pm m f_{r} \pm n f_{i}\right|
$$

Where $m=0,1,2 ; k=0,1,2,3 \ldots \ldots ; n=p, p \pm 1, p \pm 2$.

3) Ball fault for mixed eccentric motor

When the motor with mixed eccentric has an ball bearing fault, the air-gap length can be expressed as follows

$$
g_{b}(\theta, t)=g_{0}\left[1-\delta_{s} \cos \theta-\delta_{d} \cos \left(\omega_{r} t-\theta\right)\right]\left[1-e \cos \left(\omega_{\text {cage }} t+\theta\right) \sum_{k=-\infty}^{+\infty} \delta\left(t-\frac{k}{f_{b}}\right)\right]
$$

Where $f_{b}$ is the characteristic frequency for an inner raceway fault, $\omega_{\text {cage }}$ is the cage rotation angular frequency. $\left(\omega_{\text {cage }}=\omega_{r}\left(1-\left(D_{\mathrm{b}} \cos \beta\right) / D_{\mathrm{c}}\right) / 2, D_{c}\right.$ is the cage diameter; $D_{b}$ is the ball diameter and $\beta$ is the contact angle)

The magnetic flux density can be obtained using method mentioned above

$$
B(\theta, t)=F \Lambda(\theta, t)=F \Lambda_{0} \cos \left[\left(\omega_{s} \pm m \omega_{\text {cage }} \pm n \omega_{c}\right) t \pm k \theta+\varphi\right]
$$

Where $\mathrm{m}=0,1 ; \mathrm{k}=0,1,2,3 \ldots \ldots ; \mathrm{n}=\mathrm{p}, \mathrm{p} \pm 1, \mathrm{p} \pm 2$.

According to the voltage equations of induction motor, the ball fault characteristic frequency expression is shown below

$$
f_{b f}=\left|f_{s} \pm m f_{\text {cage }} \pm n f_{b}\right|
$$

Where $\mathrm{m}=0,1,2 ; \mathrm{k}=0,1,2,3 \ldots \ldots ; \mathrm{n}=\mathrm{p}, \mathrm{p} \pm 1, \mathrm{p} \pm 2$.

\section{B. Torque Vibration}

When the ball contacts the fault point (an outer raceway fault is taken an example), a mechanical resistance will appear. The consequence increases a small torque vibration to the load torque and the vibration is related to the characteristic vibration frequencies $f_{o}$. Considering the torque vibration caused by bearing fault, the load torque can be expressed by

$$
\Gamma_{\text {laod }}(t)=\Gamma_{0}+\Gamma_{c} \cos \left(\omega_{o} t\right)
$$

Where $\Gamma_{0}$ is constant component for motor torque, $\Gamma_{\mathrm{c}}$ is additional torque component caused by bearing fault, $\omega_{c}$ is bearing fault anagular.

The mechanical equation of motor is used

$$
\Gamma_{\text {motor }}(t)-\Gamma_{\text {load }}(t)=J \frac{d \omega_{r}}{d t}
$$

Combing equation (15) and (16)

$$
\omega_{r}(t)=\frac{1}{J} \int_{t}\left(\Gamma_{\text {motor }}(t)-\Gamma_{\text {load }}(t)\right) d \tau
$$

Where $\Gamma_{\text {motor }}$ is the electromagnetic torque and $J$ is the total inertia of the system.

Generally, the motor torque is considered to be equal to the constant component for motor torque, namely, $\Gamma_{0}$. Therefore, equation (3) can be re-written as follows

$$
\omega_{r}(t)=-\frac{\Gamma_{c}}{J \omega_{c}} \sin \left(\omega_{o} t\right)+\omega_{r 0}
$$

Using the formula $\omega=d \theta / d t$, the rotor position $\theta_{r}$ can be obtaioned

$$
\theta_{r}(t)=\int_{t_{0}}^{t} \omega_{r}(\tau) d \tau=\frac{\Gamma_{o}}{J \omega_{o}^{2}} \cos \left(\omega_{o} t\right)+\omega_{r 0} t
$$

Because the mixed eccentricity can cause the torque vibration for motor, so the phase modulation to the MMF occurs and rotor MMF expression for is as follows

$$
F_{r}(\theta, t)=F_{r} \cos \left(p \theta_{r}-s \omega_{s} t+A_{r} \cos \left(\omega_{r} t\right)\right)
$$

Where $\mathrm{A}_{\mathrm{r}} \cos \left(\omega_{r} t\right)$ represents the modulation angle because of eccentric and $s$ is the motor slip.

And

$$
\theta_{r}=\int_{0}^{t} \omega_{r} d t+\theta^{\prime}
$$

Where $\theta^{\prime}$ is mechanical angle in the rotor reference frame.

Due to the rotor and stator reference frame has a relationship $\theta=\theta^{\prime}+\theta_{r}$, using equation (21), the mechanical angle $\theta^{\prime}$ can be obtained

$$
\theta^{\prime}=\theta-\omega_{r 0} t-A_{o} \cos \left(\omega_{o} t\right)
$$

Where $A_{o}=\Gamma_{c} / J \omega_{0}^{2}$.

Therefore, the rotor MMF can be obtained refer to the stator reference frame 
$F_{r}(\theta, t)=F_{r} \cos \left(p \theta-\omega_{s} t-p A_{o} \cos \left(\omega_{o} t\right)-A_{r} \cos \left(\omega_{r} t\right)\right)$

It is easy to get the flux magnetic density using equation (7)

$B(\theta, t)=F_{r}(\theta, t) \Lambda_{0}=F_{r} \Lambda_{0} \cos \left(p \theta-\omega_{s} t-A_{r} \cos \left(\omega_{r} t\right)-p A_{o} \cos \left(\omega_{o} t\right)\right)(24)$

According to the voltage equations of induction motor, the outer raceway fault characteristic frequency expression is shown below

$$
f_{o f}=\left|f_{s} \pm m f_{r} \pm n f_{o}\right|
$$

Where $\mathrm{m}=0,1,2,3 \ldots \ldots ; \mathrm{n}=0,1,2,3 \ldots \ldots$.

If the bearing has an inner raceway fault or ball fault, the same method can be used to do analysis, and the same result can be obtained.

TABLE I: EIGENFREQUENCIES FOR MOTOR WITH ECCENTRIC OR WITHOUT ECCENTRIC.

\begin{tabular}{|l|c|c|c|c|}
\hline & \multicolumn{3}{|c|}{ Bearing fault for induction motor } \\
\hline & \multicolumn{2}{|c|}{ Without eccentric } & \multicolumn{2}{c|}{ With eccentric } \\
\hline & $\begin{array}{c}\text { Air-gap } \\
\text { length change }\end{array}$ & $\begin{array}{c}\text { Torque } \\
\text { vibration }\end{array}$ & $\begin{array}{c}\text { Air-gap } \\
\text { length change }\end{array}$ & $\begin{array}{c}\text { Torque } \\
\text { vibration }\end{array}$ \\
\hline $\begin{array}{l}\text { Outer } \\
\text { raceway }\end{array}$ & $f_{s} \pm k f_{o}$ & $f_{s} \pm k f_{o}$ & $f_{s} \pm f_{r} \pm k f_{o}$ & $f_{s} \pm m f_{r} \pm n f_{o}$ \\
\hline Inner raceway & $f_{s} \pm f_{r} \pm k f_{i}$ & $f_{s} \pm k f$ & $\begin{array}{c}f_{s} \pm f_{r} \pm k f_{i} \\
f_{s} \pm 2 f_{r} \pm k f_{i}\end{array}$ & $f_{s} \pm m f_{r} \pm n f_{i}$ \\
\hline \multicolumn{1}{|c|}{ Ball } & $f_{s} \pm f_{\text {cage }} \pm k f_{b}$ & $f_{s} \pm k f_{b}$ & $\begin{array}{c}f_{s} \pm f_{\text {cage }} \pm k f_{b} \\
f_{s} \pm 2 f_{\text {cage }} \pm k f_{b}\end{array}$ & $\begin{array}{c}f_{s} \pm m f_{\text {cage }} \pm \\
n f_{b}\end{array}$ \\
\hline
\end{tabular}

\section{SIMULATION}

Based on the $\alpha \beta$ coordinate system, the simulation model for eccentric motor is established with voltage equation, flux linkage equation, torque equation and movement equation with the method in paper [6]. By adding an additional periodic torque pulse to the simulation model, the pulse frequency for all kinds of bearing fault can be calculated using the equation in work [7]. The stator current spectrum can be obtained for different cases and results are shown in Fig.1 to Fig.3. (only the outer raceway fault is simulated, because the simulation method for inner raceway fault and ball fault are the same. $f_{c}$ represents the characteristic frequency for an outer raceway bearing fault.)

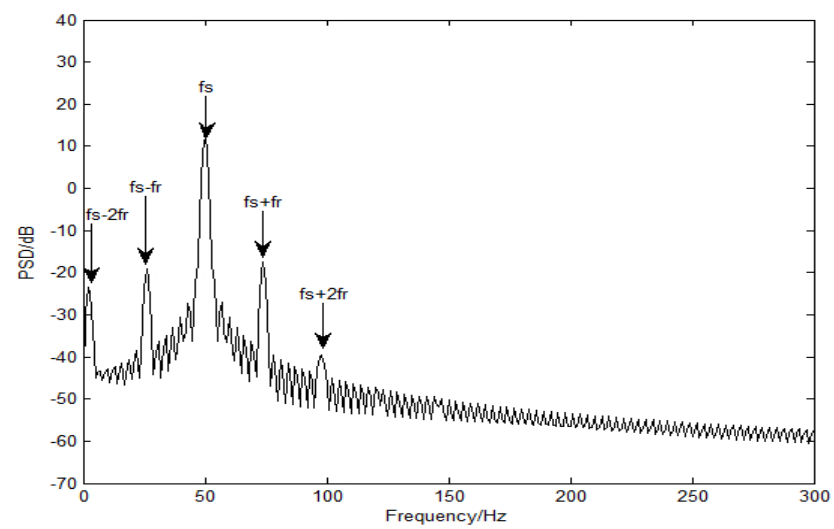

FIGURE I: SPECTRUM FOR MOTOR WITH ECCENTRICITY.

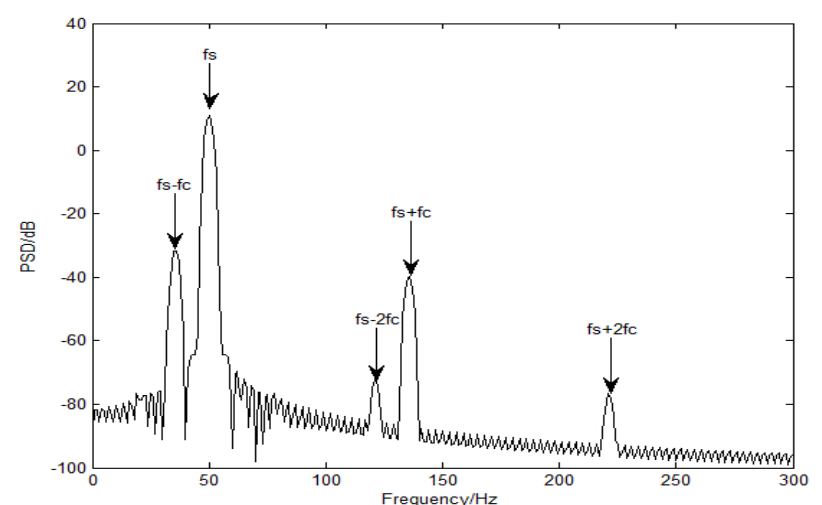

FIGURE II: SPECTRUM FOR IDEAL MOTOR WITH BEARING FAULT.

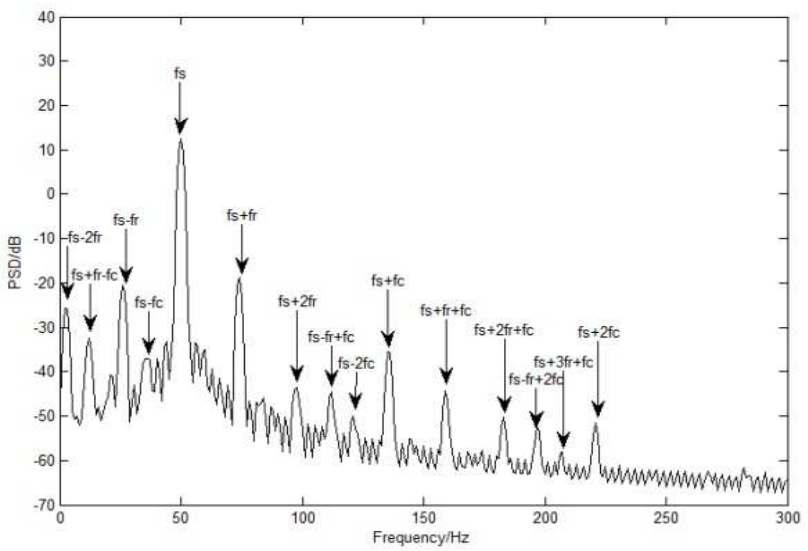

FIGURE III. SPECTRUM FOR MOTOR WITH ECCENTRIC AND BEARING FAULT.

Fig 1 and Fig 2 show stator current spectrum for eccentric motor and for motor with bearing fault respectively and the result is match with existed studies (eccentric motor for $\left|f_{s} \pm k f_{c}\right|$ and motor with bearing fault for $\left.\left|f_{s} \pm k f_{r}\right|\right)$. Fig 3 shows the spectrum for motor has both eccentric and bearing fault. The result shows that some new frequencies $\left(\left|f_{s} \pm m f_{c} \pm n f_{r}\right|\right)$ occur, expect for $\left|f_{s} \pm k f_{c}\right|$ and $\left|f_{s} \pm k f_{r}\right|$. It is because that there is an intermodulation between the eigenfrequencies for eccentric and eigenfrequencies for bearing fault.

\section{CONCLUSION}

If the eccentric motor has bearing fault, the air-gap length would be further changed and torque vibration would occur. Both of the air-gap length and torque vibration can cause the modulation to MMF (air-gap length change cause the amplitude modulation to MMF, and torque vibration cause the phase modulation to MMF), then the modulation would be translated from MMF to flux magnetic density $\mathrm{B}$, magnetic flux $\Phi$, finally to the stator current. Compared to the motor without eccentric, some new frequencies occur. The result can be considered the intermodulation between the eccentric eigenfrequencies and the bearing fault eigenfrequencies. Those new frequencies would be useful for online diagnosis for the motor in service. 


\section{ACKNOWLEDGEMENTS}

This research is supported by the National Natural Science Foundation of China (51279020). The support is greatly appreciated.

\section{REFERENCES}

[1] Trajin B, Regnier J. \& Faucher J. Indicator for bearing fault detection in asynchronous motors using stator current spectral analysis. Industrial Electronics, 2008. ISIE 2008. IEEE International Symposium on, vol., no., pp.570,575, June 30 2008-July 22008.

[2] Jaehoon K. Inseok Y. Donggil K. Hamadache, M. \& Dongik L. Bearing fault effect on induction motor stator current modeling based on torque variations. Control, Automation and Systems (ICCAS), 2012 12th International Conference on, vol., no., pp.814,818, 17-21 Oct. 2012

[3] Faiz J. \& Ojaghi M. Unified winding function approach for dynamic simulation of different kinds of eccentric faults in cage induction machines. Electric Power Applications, IET, vol.3, no.5, pp.461,470, September 2009.

[4] Dorrell, D.G. Thomson W.T. \& Roach, S. Analysis of airgap flux, current, and vibration signals as a function of the combination of static and dynamic airgap eccentric in 3-phase induction motors. Industry Applications, IEEE Transactions on , vol.33, no.1, pp.24,34, Jan/Feb 1997.

[5] L.J. Sun, X.Z.Lv, H.L. Liu. \& C.X. Zhang. The rotor eccentric fault detection and diagnosis for asynchronous motor based on the DSO 2100 [J]. Journal of motor and control, 2005 practices: 20-23.

[6] B.S. Chen. Electric drive automatic control system, China machine press. 2003.

[7] Schoen, R.R. Habetler, T.G. Kamran, F. \& Bartfield, R.G. Motor bearing damage detection using stator current monitoring, Industry Applications, IEEE Transactions on, vol.31, no.6, pp.1274,1279, Nov/Dec 1995. 